\title{
VEDA E VERMIFUGAÇÃO COMO ALTERNATIVAS DE MANEJO PARA DESMAMA DE BEZERROS NELORE EM PASTAGEM NATIVA DO PANTANAL ${ }^{1}$
}

\author{
JOSÉ ROBSON BEZERRA SERENO ${ }^{2}$, JOÃO BATISTA CATTO ${ }^{3}$, \\ MARTA PEREIRA DA SILVA ${ }^{4}$ eFABIANA TAVARES PIRES DE SOUZA SERENO ${ }^{5}$
}

\begin{abstract}
RESUMO - Entre março de 1992 e janeiro de 1993 realizou-se este estudo com o objetivo de avaliar o efeito integrado da veda do pasto nativo com o controle estratégico de nematóides gastrintestinais no desempenho corporal de bezerros Nelore pós-desmame no Pantanal da Nhecolândia, MS, Brasil. Dois lotes de animais recém-desmamados aos nove meses foram colocados em invernadas contíguas de pastagens nativas com as mesmas características fisionômicas, que foram vedadas por três meses e meio; a invernada do lote controle foi previamente pastejada por vacas com bezerro ao pé para contaminação. O lote tratado permaneceu com níveis muito baixos de ovos por grama de fezes durante todo o período experimental, e no lote controle foram diminuindo no decorrer do ensaio, terminando semelhantes. No desenvolvimento corporal, observou-se menor perda de peso do lote tratado durante a estação seca e ganho de peso compensatório do lote controle na estação chuvosa subseqüente. Os pesos médios dos dois lotes no final do experimento foram semelhantes.
\end{abstract}

Termos para indexação: controle de nematóides, helmintoses, gado de corte, melhoramento de pastagem, alimentação animal.

\section{ALTERNATIVE MANAGEMENT FOR WEANED NELORE CALVES IN THE PANTANAL'S NATIVE PASTURES}

\begin{abstract}
The aim of this study was to investigate the integrated effects of native pastures sealing with strategic control of gastrointestinal nematodes on body development of weaned Nellore calves, studied between March 1992 and January 1993 in the Pantanal region, Brazil. Two homogeneous groups of weanling calves were put on contiguous paddocks of native pastures with the same physiognomic characteristics and sealed for three and a half months. The paddock where the non-treated group was put, was previously used by cows that were rearing a calf for contamination of the pasture. The treated group remained with low levels of eggs per gram of feces (EGF) during the whole experimental period. In the non-treated group, the EGF diminished during the assay, ending with similar levels of the treated group. On body development, it was observed a lower body weight loss of the treated group during the dry season and a compensatory weight gain of the non-treated group on the subsequent rainy season. The mean body weight of the two groups was similar at the end of the trial.
\end{abstract}

Index terms: nematode control, helminthoses, beef cattle, pasture improvement, animal feeding.

${ }^{1}$ Aceito para publicação em 14 de janeiro de 2000.

${ }^{2}$ Méd. Vet., M.Sc., Embrapa-Centro de Pesquisa Agropecuária do Pantanal (CPAP), Caixa Postal 109, CEP 79320-900 Corumbá, MS. E-mail: sereno@cpap.embrapa.br

${ }^{3}$ Méd. Vet., Dr., Embrapa-Centro Nacional de Pesquisa de Gado de Corte (CNPGC), Caixa Postal 154, CEP 79106-000 Campo Grande, MS. E-mail: catto@cnpgc.embrapa.br.

${ }^{4}$ Zootec., Dra., Embrapa-CNPGC.

E-mail: martha@cnpgc.embrapa.br

${ }^{5}$ Biól., M.Sc., Dep. de Genética, Universidade de Córdoba, Espanha. Bolsista de Desenvolvimento Regional CNPq/ Embrapa-CPAP. E-mail: ge2pisef@uco.es

\section{INTRODUÇÃO}

No Pantanal a desmama de bezerros ocorre em torno de oito a dez meses de idade. A adoção de um período de desmama com idade avançada proporciona desgastes nutricionais nas vacas, em virtude da maior necessidade de nutrientes para suprir a manutenção, a lactação e a atividade ovariana, com conseqüente aumento do intervalo entre partos (IEP). A desmama tardia associada aos períodos críticos 
de disponibilidade na quantidade e qualidade das pastagens nativas (Pott et al., 1989) é um dos motivos da baixa taxa da desmama no Pantanal (40\%-54\%).

Testando o efeito da desmama antecipada em vacas de cria na sub-região da Nhecolândia, Tullio et al. (1980) verificaram que vacas com bezerros desmamados aos quatro meses tiveram IEP $(454 \pm 60)$, aproximadamente, dois meses menor que vacas com bezerros desmamados aos seis meses $(518 \pm 56)$ e estas apresentaram IEP menor quando comparadas àquelas cujos bezerros foram desmamados aos oito me-

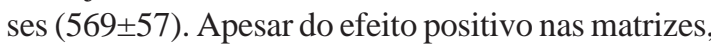
os bezerros desmamados aos quatro, seis e oito meses pesaram em média, aos 12 meses, 109, 129 e $148 \mathrm{~kg}$, e aos 18 meses, 176, 198 e 220, respectivamente (Tullio \& Brum, 1980). Almeida et al. (1994) encontraram resultados semelhantes na sub-região dos Paiaguás, onde vacas com bezerros desmamados aos seis e oito meses tiveram IEP significativamente menor que vacas com bezerros desmamados aos 10 meses.

Nos últimos anos observou-se uma mudança radical na forma de comercialização dos animais no Pantanal, cuja venda atual de bezerros após a desmama via leilões regionais tem se tornado uma alternativa vantajosa em relação à venda de animais adultos. No entanto, de acordo com Tullio \& Brum (1980) o desmame antecipado em pastagens nativas como estratégia para aumentar a natalidade esbarra no desenvolvimento dos bezerros até os 12-18 meses de idade.

Os nematóides gastrintestinais estão entre as principais causas de baixa produtividade dos rebanhos bovinos no Brasil. Existem épocas do ano em que as condições do meio ambiente são favoráveis ao desenvolvimento e migração das larvas infestantes, sendo observada uma variação estacional no número de larvas encontradas nas pastagens (Melo, 1977).

O parasitismo por helmintos gastrintestinais tem sido apontado como uma das possíveis causas do baixo desenvolvimento de bovinos de corte no Pantanal (Catto \& Ueno, 1981). No entanto, Catto \& Furlong (1982) estudaram vários esquemas de tratamentos anti-helmínticos para bovinos no Pantanal, nos quais os animais compartilham a mesma pastagem, e não evidenciaram efeito significativo no ganho de peso de bezerros antes e após a desmama. Posteriormente, em outro estudo, Catto et al. (1993) corrigiram o efeito invernada na resposta ao tratamento anti-helmíntico e concluíram que bovinos criados em pastagens nativas na região do Pantanal devem ser tratados com anti-helmínticos na primeira estação seca após a desmama, sendo desnecessário o tratamento estratégico em épocas subseqüentes.

Estudando o desenvolvimento e sobrevivência de larvas de nematóides gastrintestinais de bovinos, Catto $(1982,1987,1989)$ concluiu que a veda do pasto por dois meses, durante ou no final da estação chuvosa, diminuiu acentuadamente o número de larvas no pasto, e recomendou a veda da pastagem nativa nesse período como estratégia para melhorar a alimentação e diminuir o parasitismo em bezerros na primeira estação seca pós-desmama.

Este estudo teve como objetivo avaliar o efeito integrado de veda do pasto e controle estratégico de nematóides no desenvolvimento de bezerros desmamados aos seis-sete meses de idade em pastagens nativas do Pantanal comparado ao manejo tradicional.

\section{MATERIAL E MÉTODOS}

O ensaio foi conduzido na fazenda Nhumirim (latitude $18^{\circ} 59^{\prime} 0 " \mathrm{~S}$, longitude $56^{\circ} 39^{\prime} 0^{\prime \prime} \mathrm{W}$ e altitude $98 \mathrm{~m}$ ), de propriedade da Embrapa-Centro de Pesquisa Agropecuária do Pantanal, localizada na sub-região da Nhecolândia, Município de Corumbá, MS. O clima do Pantanal é tropical subúmido, do tipo Aw, de Köppen, com uma estação chuvosa de outubro a março e uma relativamente seca observada de abril a setembro, segundo Cadavid Garcia (1984).

O ensaio foi realizado no período de março de 1992 a fevereiro de 1993, observando-se no período precipitação pluviométrica média mensal de 107,2 mm, com máxima no mês de dezembro (200,7 mm) e mínima em junho (2,0 mm), de acordo com o Boletim Agrometeorológico (1997).

Utilizaram-se 205 bezerros da raça Nelore recém-desmamados, os quais foram criados e recriados nas condições de meio ambiente do Pantanal. Em 15/3/92, todos os animais foram postos em uma invernada de 20 ha, durante 15 dias, com o objetivo de atenuar o estresse pós-desmama. Em 30/3/92, os 205 animais foram divididos em dois grupos distintos, mantendo-se a maior homogeneidade possível com relação a sexo e peso médio $(137 \mathrm{~kg})$, sendo posteriormente colocados em invernadas contíguas, de 150 ha cada, com taxa de lotação de $0,21 \mathrm{UA} / \mathrm{ha}$. 
O grupo A (desafio) foi everminado com Levamisol na dosagem de $1 \mathrm{~mL}$ para cada $40 \mathrm{~kg}$ de peso vivo, via subcutânea, nas seguintes datas: 30/3, 14/5 e 29/9/92. Para elevar a disponibilidade de pastagem e diminuir a infestação por larvas de nematóides, a invernada foi vedada por três meses e meio, no período que antecedeu a desmama. Fez-se o rebaixamento da pastagem com roçadeira mecânica logo antes da introdução dos animais.

O grupo B (controle), que não foi everminado, foi alojado em uma invernada contígua com as mesmas características da anterior, ou seja, veda de 3,5 meses e taxa de lotação de 0,21 UA/ha. Entretanto, para o rebaixamento da pastagem, utilizaram-se 150 vacas com bezerro ao pé, por 15 dias consecutivos, com o objetivo de contaminar o pasto com larvas de nematóides e simular o que ocorre em condições de manejo tradicional.

Os animais foram pesados mensalmente, e o nível de infestação por nematóides foi monitorado mediante exames parasitológicos de fezes, nos quais fazia-se a contagem de ovos por grama de fezes (OPG) durante toda a fase experimental.

Com o objetivo de estimar a qualidade e disponibilidade da pastagem, foram realizadas avaliações nos meses de março, maio e outubro de 1992, e em janeiro de 1993, de acordo com metodologia proposta por Brow (1954). Para as avaliações de março e maio de 1992, utilizou-se um quadrado de 0,5 x 0,5 m e dividiu-se a área de cada invernada em sítios ecológicos, ou seja, ambientes homogêneos com dominância de uma gramínea: campo de rabo-de-burro (Andropogon bicornis), campo de mimoso (Axonopus purpusii), caronal (predomínio de Elyonurus muticus), baixada (A. bicornis, A. purpusii, Panicum laxum, Mesosetum chasae e Paspalum plicatulum) e campo de Andropogon selloanus. Nesta avaliação foram usadas 56 amostras por ambiente. A vegetação herbácea de cada quadrado foi cortada rente ao solo com tesoura, e imediatamente feita a separação botânica em gramíneas dominantes e matéria morta. O material foi colocado em sacos de papel e levado ao laboratório para determinação da matéria seca. Nas outras duas avaliações (outubro de 1992 e janeiro de 1993), utilizou-se o método do Botanal (Tothill et al., 1978), em que a vegetação foi amostrada em três transectos que abrangiam os diferentes sítios ecológicos, totalizando 100 amostras por invernada. Também foram coletadas amostras por invernada para a determinação da proteína bruta (PB) nos meses de março e maio.

Para composição e análise crítica, utilizou-se o SAS Statistical Analysis System (SAS Institute, 1985), adotando-se o seguinte modelo:

$\mathrm{Y}=\mu+$ trat + tempo + erro onde:
Y = variáveis respostas peso ou nível de infestação;

$\mu=$ efeito médio geral;

trat $=$ efeito de tratamento;

tempo = efeito de tempo;

erro $=$ erro aleatório associado a Y.

\section{RESULTADOS E DISCUSSÃO}

Não houve diferença significativa na disponibilidade de matéria seca das pastagens entre grupos experimentais, em virtude da proximidade das invernadas (contíguas), as quais possuíam as mesmas características de solo e vegetação. A disponibilidade de pastagem nas épocas avaliadas variaram de $1.760 \mathrm{~kg} / \mathrm{ha}$ (maio/92) a $5.244 \mathrm{~kg} / \mathrm{ha}$ (janeiro/93) de matéria seca (Fig. 1). Esses meses, em geral, correspondem, respectivamente, ao final do período de chuva, de acordo com os dados meteorológicos da região.

O método de avaliação destrutivo (cortes) que foi utilizado nas primeiras avaliações, apesar de oferecer maior precisão, era mais trabalhoso e gastava-se demasiado tempo para cobrir uma pequena área de vegetação. Por essa razão, utilizou-se posteriormente o método Botanal, que além de não ser destrutivo, permite a obtenção de maior número de áreas amostradas em menor tempo.

A oferta de pastagem observada nas invernadas deste experimento indicam a possibilidade de aumento da taxa de lotação para essa categoria animal, considerando a lotação média para o Pantanal, de 0,32 UA/ha, segundo Cadavid Garcia (1981). Mesmo com a relativa folga na taxa de lotação obser-

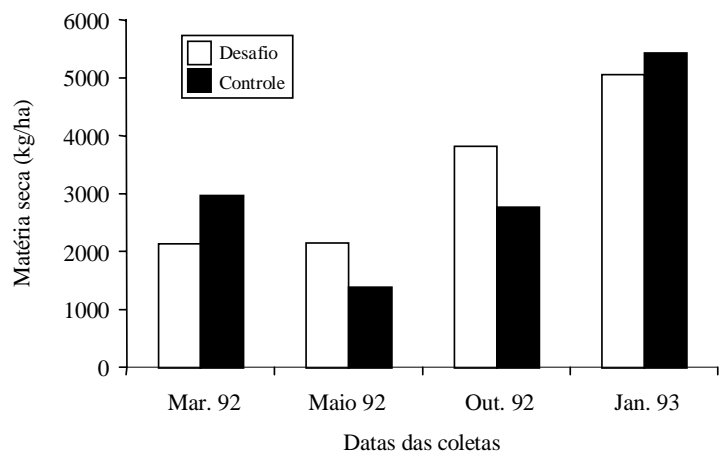

FIG.1. Disponibilidade de pastagem nas invernadas dos grupos desafio e controle em diferentes épocas do ano na fazenda Nhumirim, Pantanal da Nhecolândia.

Pesq. agropec. bras., Brasília, v.35, n.10, p.2099-2105, out. 2000 
vada, de 0,32 UA/ha, mais estudos devem ser desenvolvidos sobre esse tema no Pantanal, para melhor conhecer o comportamento dessa variável, considerada de extrema importância para o desenvolvimento da pecuária extensiva pantaneira.

A análise da produção de matéria seca (MS) por sítios ecológicos nos meses de março e maio revelou que existem diferenças entre ambientes, observando-se maior produção em campo de rabo-de-burro $(2.700 \mathrm{~kg} / \mathrm{ha}$ de MS) e caronal (3.655,1 kg/ha de MS). As gramíneas em questão são cespitosas de porte alto e pouco palatáveis, aliado ao fato de essas invernadas não terem sido queimadas havia pelo menos três anos, revelando acúmulo de MS da ordem de $10 \%$ a $25 \%$ em relação ao solo.

As menores disponibilidades foram observadas nos ambientes borda de baía, seguida de campo de mimoso e campo de Andropogon selloanus, 1.183,9; $1.705,63$ e $1.986,1 \mathrm{~kg} / \mathrm{ha}$ de MS, respectivamente. Essa menor disponibilidade é conseqüência de melhor qualidade das forrageiras mais consumidas nessas áreas mais inundáveis.

Nas avaliações das pastagens realizadas nos meses de outubro e janeiro (Fig. 1), as espécies que mais contribuíram na biomassa aérea total foram: A. purpusii e A. bicornis, sendo a primeira, segundo Allem \& Valls (1987), considerada por fazendeiros a forrageira mais importante para nutrição do rebanho da Nhecolândia e Paiaguás, não ocorrendo o mesmo com $A$. bicornis, que só é consumida pelos bovinos no início do período de crescimento (início das chuvas) ou após a queima. Observou-se maior disponibilidade de pastagem nos meses de outubro e janeiro, sendo 3.289 e $5.244 \mathrm{~kg} / \mathrm{ha}$ de MS, respectivamente, o que permite que essas pastagens suportem uma taxa de lotação maior ( 0,5 a $0,8 \mathrm{UA} / \mathrm{ha})$ nesse período. Vale salientar que a biomassa observada nesses meses é reflexo do mês anterior, quando o início das chuvas ocorreu em setembro e os meses mais chuvosos foram outubro e dezembro, respectivamente (Fig. 2).

As porcentagens de proteína bruta (PB), que não variaram muito entre espécies e invernadas/períodos, em torno de $6 \%$ PB, e os valores médios nos períodos estudados, constam da Tabela 1. Os valores de PB observados neste estudo são considerados muito baixos para suprir as necessidades dos animais jovens, ou seja, de 14\% de PB. Entretanto, espécies como Leersia hexandra, Setaria geniculata, Panicum repens, Paspalum plicatulum e Mesosetum chaseae tiveram valores que variavam de $6 \%$ a $12 \%$ de PB, permitindo aos animais, via seletividade, suprir as necessidades de proteína disgestível e ganhar peso no período chuvoso (Fig. 3). Não foi possível analisar os valores de PB em Axonopus purpussi; entretanto, estudo de Comastri Filho (1984) demonstra que esses valores são da ordem de $6,6 \%$ de PB.

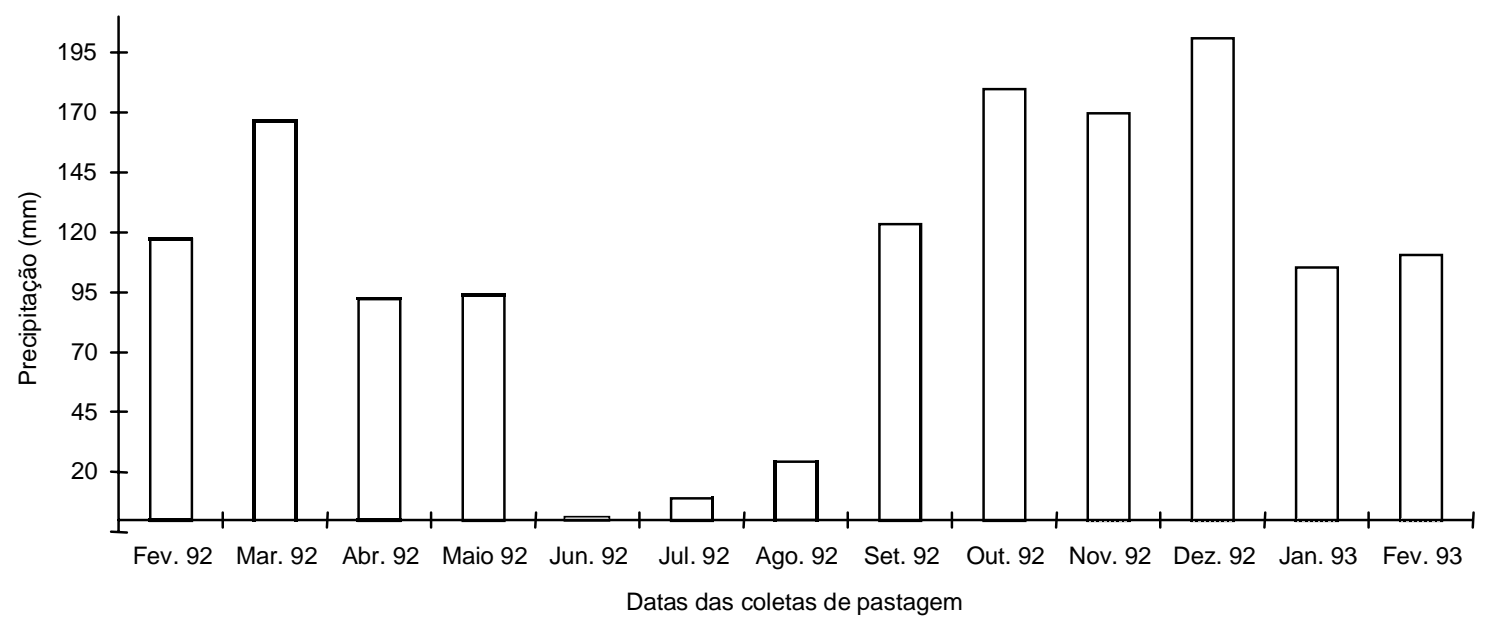

FIG. 2. Precipitação pluvial observada durante os 13 meses de estudo na fazenda Nhumirim, Pantanal da Nhecolândia. 
Na Fig. 4 e Tabela 2 encontram-se o OPG de nematóides do grupo desafio e controle, bem como seus respectivos pesos no início e final do experimento. Em 30/3, data da primeira vermifugação, não foram realizados exames de fezes. A infecção do grupo controle foi diminuindo com a idade dos animais, ficando em nível semelhante à do grupo desafio no término do ensaio. $\mathrm{O}$ grupo desafio continuava em $14 / 5$, na segunda vermifugação, com níveis baixos, permanecendo assim até o final de setembro, na terceira e última vermifugação.

TABELA 1. Porcentagem média de proteína bruta de algumas espécies de gramíneas nativas do Pantanal em março e maio de 1992.

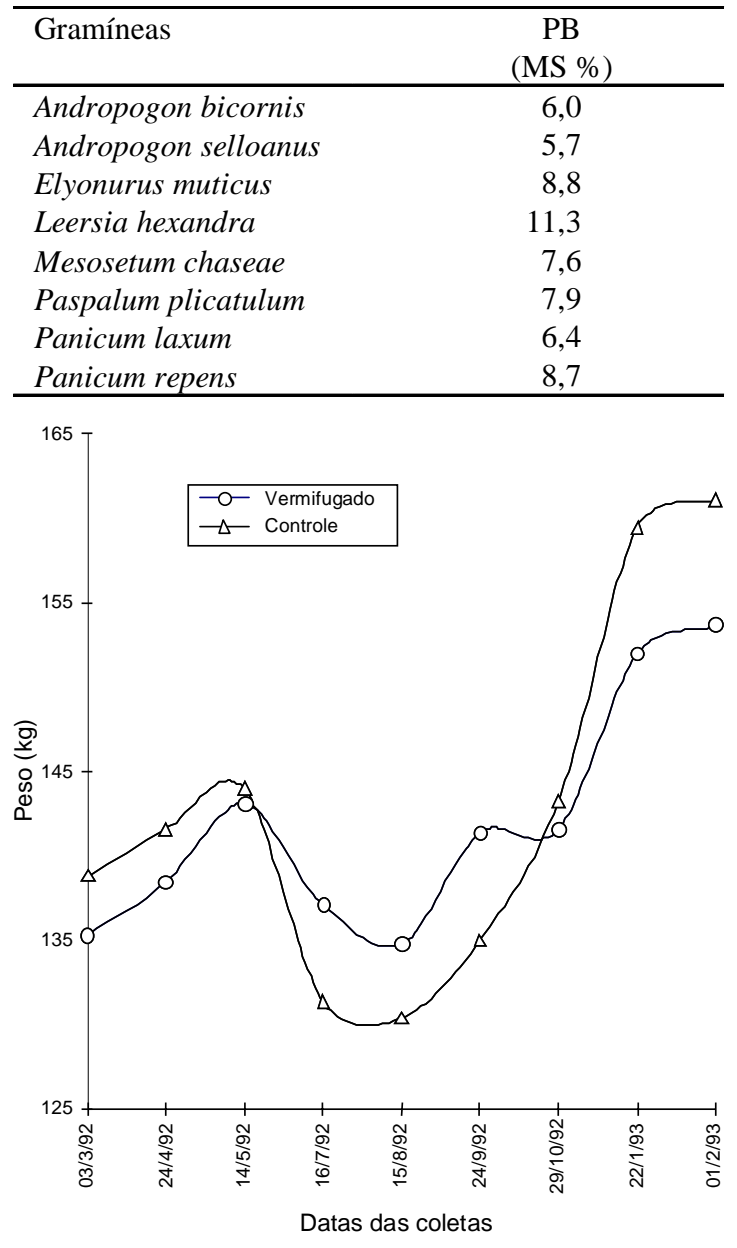

FIG. 3. Desempenho corporal de bezerros Nelore após desmama no Pantanal da Nhecolândia, MS.
O comportamento da infecção de bezerros no grupo desafio corrobora a hipótese de Catto (1989), de que a veda do pasto no final da estação chuvosa reduz drasticamente a infestação da pastagem por larvas infectantes.

Apesar de os animais desafio permanecerem com níveis baixos de infestação parasitária durante todo o período, não ocorreu diferença significativa $(\mathrm{P}>0,05)$ no ganho de peso e no peso final dos animais de 14/5/92 a 23/9/92, período de baixa precipitação pluviométrica, considerado crítico pela baixa disponibilidade e qualidade do pasto. Os animais do grupo desafio tiveram melhor desempenho corporal do que o grupo controle. Posteriormente, com o início das chuvas em setembro/outubro e maior disponibilidade de pasto, o grupo controle teve ganho de peso compensatório. Em outro experimento realizado por Catto et al. (1993), nas mesmas invernadas, no período de um ano pós-desmama, bezerros desmamados

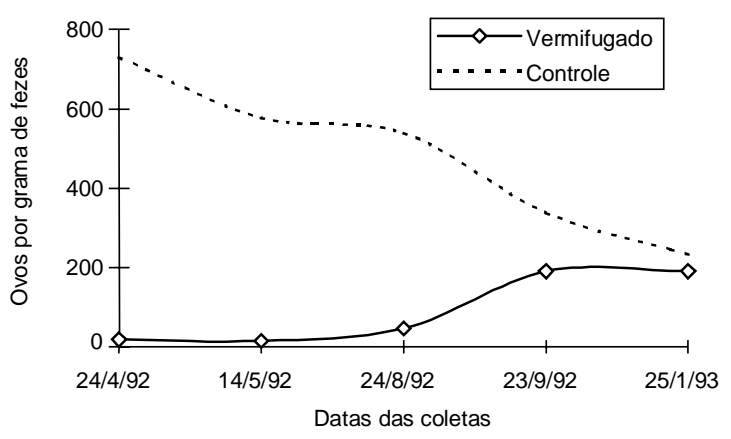

FIG.4. Média de ovos por gramas de fezes de bezerros desmamados no Pantanal da Nhecolândia.

TABELA 2. Média do nível de infestação de ovos por grama de fezes (OPG), coeficiente de variação, pesos iniciais e finais, e ganho de peso médio de bezerros Nelore desmamados no Pantanal da Nhecolândia ${ }^{1}$.

\begin{tabular}{|c|c|c|c|c|c|c|c|}
\hline \multirow[t]{2}{*}{ Tratamento } & \multicolumn{2}{|c|}{ OPG } & \multirow{2}{*}{$\begin{array}{l}\mathrm{CV} \\
(\%)\end{array}$} & \multicolumn{2}{|c|}{$\mathrm{P}(\mathrm{kg})$} & \multirow{2}{*}{$\begin{array}{l}\mathrm{CV} \\
(\%)\end{array}$} & \multirow{2}{*}{$\begin{array}{l}\text { Ganho de peso } \\
\text { médio }(\mathrm{kg})\end{array}$} \\
\hline & Inicial & Final & & Inicial & Final & & \\
\hline$\overline{\mathrm{A}}$ & $18 \mathrm{a}$ & $190 \mathrm{~b}$ & 53 & $135 \mathrm{a}$ & $154 a$ & 7 & $18,36 \mathrm{a}$ \\
\hline B & $730 \mathrm{~b}$ & $233 b$ & 15 & $139 a$ & $161 \mathrm{a}$ & 8 & $22,21 \mathrm{a}$ \\
\hline
\end{tabular}

${ }^{1}$ Médias, nas colunas, seguidas da mesma letra, não diferem $(\mathrm{P}<0,05)$ pelo teste $\mathrm{t}$ de Student. 
tiveram ganho de peso aproximado de $50 \mathrm{~kg}$, muito superior aos $20 \mathrm{~kg}$ verificados neste estudo. Como as condições climáticas foram semelhantes em ambos os trabalhos, a justificativa mais provável é que a veda do pasto por um período muito prolongado tenha provocado queda na qualidade das pastagens nativas. Durante a vedação prolongada as pastagens perdem boa parte do valor nutritivo, o qual pode ser reposto com a utilização de sais proteinizados, já em uso em algumas propriedades pantaneiras. Contudo, no caso específico da cria, essa necessidade é amenizada pelas menores exigências nutricionais dos animais, se comparadas com as da recria e da engorda.

Portanto, embora a veda do pasto e tratamento estratégico tenham permitido aos animais do grupo desafio permanecer com baixos níveis de infecção (Tabela 2) durante a estação seca, possibilitando menor perda de peso durante esse período, o ganho de peso compensatório do grupo controle na estação chuvosa subseqüente equivaleu a esse efeito positivo de tratamento.

A veda do pasto nativo por um período de três meses e meio no final do período chuvoso, ao contrário do que se esperava, não propiciou melhor desempenho de bezerros desmamados na estação seca. Os resultados obtidos do sistema produtivo no presente trabalho comprovam os observados anteriormente na região do Pantanal em pastagens nativas: a veda do pasto no final da estação chuvosa reduz drasticamente a infestação das pastagens por larvas infectantes de nematóides gastrintestinais; a everminação tem efeito significativo no ganho de peso apenas na primeira estação seca pós-desmama. Após essa época o ganho de peso compensatório iguala os animais.

\section{CONCLUSÕES}

1. A veda do pasto, realizada por período de três meses e meio é considerada longa e não traz efeitos benéficos sobre a qualidade da pastagem.

2. A veda do pasto é eficaz na redução de larvas infectantes de nematóides gastrintestinais nas pastagens nativas do Pantanal da Nhecolândia.

\section{REFERÊNCIAS}

ALLEM, A.C.; VALLS, J.F.M. Recursos forrageiros nativos do Pantanal Mato-Grossense. Brasília : Embrapa-Cenargen, 1987. 339p. (EmbrapaCenargen. Documentos, 8).

ALMEIDA, I.L.; BRUM, P.A.R.; TULLIO, R.R.; AROEIRA, J.A.D.C.; POTT, E.B. Desempenho reprodutivo de bovinos na sub-região dos Paiaguás do Pantanal Mato-Grossense. Pesquisa Agropecuária Brasileira, Brasília, v.29, n.3, p.461465, mar. 1994.

BOLETIM AGROMETEOROLÓGICO: 1986-1996 (Fazenda Nhumirim). Corumbá : Embrapa-CPAP, v.3, 1997. 81p.

BROW, D. Methods of surveying and measuring vegetation. Hurley, Berks : Commonwealth Bureau of Pasture and Field Crops, 1954. 223p. (Bulletin, 42).

CADAVID GARCIA, E.A. O clima no Pantanal MatoGrossense, Corumbá. Corumbá : Embrapa-CPAP, 1984. 39p. (Embrapa-CPAP. Circular Técnica, 14).

CADAVID GARCIA, E.A. Índices técnico-econômicos da região do Pantanal Mato-Grossense. Corumbá : Embrapa-UEPAE de Corumbá, 1981. 81p. (Circular Técnica, 7)

CATTO, J.B. Desenvolvimento e sobrevivência de larvas de nematóides gastrintestinais de bovinos, durante a estação seca, no Pantanal Mato-Grossense. Pesquisa Agropecuária Brasileira, Brasília, v.17, n.6, p.923-927, jun. 1982.

CATTO, J.B. Efeito do descanso de pastagens na disponibilidade de larvas infectantes de nematóides na região do Pantanal Mato-Grossense. Pesquisa Agropecuária Brasileira, Brasília, v.24, n.8, p.10371039, ago. 1989.

CATTO, J.B. Longevidade de larvas infectantes de nematóides gastrintestinais de bovinos no Pantanal Mato-Grossense. Pesquisa Agropecuária Brasileira, Brasília, v.22, n.8 , p.847-854, ago. 1987.

CATTO, J.B.; BARROS, A.T.; COSTA, C.A. Efeito de tratamento anti-helmíntico no ganho de peso de bezerros desmamados, criados em pastagens nativas, no Pantanal Mato-Grossense, Brasil. Revista Brasileira de Parasitologia Veterinária, São Paulo, v.2, n.2, p.127-132, 1993. 
CATTO, J.B.; FURLONG, J. Desenvolvimento de bovinos criados extensivamente, submetidos a vários esquemas de tratamentos anti-helmínticos, no Pantanal Mato-Grossense. Pesquisa Agropecuária Brasileira, Brasília, v.17, n.1, p.131-136, jan. 1982.

CATTO, J.B.; UENO, A. Nematóides gastrointestinais em bovinos zebu no Pantanal Mato-Grossense. I. Prevalência, intensidade de infecção e variação estacional. Pesquisa Agropecuária Brasileira, Brasília, v.16, n.1, p.129-140, jan. 1981.

COMASTRI FILHO, J.A. Pastagens nativas e cultivadas no Pantanal Mato-Grossense. Corumbá : Embrapa-UEPAE de Corumbá, 1984. 48p. (Embrapa-UEPAE de Corumbá. Circular Técnica, 13).

MELO, H.J.H. População de larvas infestantes de nematóides gastrintestinais de bovinos nas pastagens, durante a estação seca, em zona de cerrado do sul de Mato Grosso. Arquivo da Escola Veterinária, Belo Horizonte, v.29, n.1, p.89-95, 1977.

POTT, E.B.; CATTO, J.B.; BRUM, P.A.R. Períodos críticos de alimentação para bovinos em pastagens nativas, no Pantanal Mato-Grossense. Pesquisa Agropecuária Brasileira, Brasília, v.24, n.11, p.1427-1432, nov. 1989.
SAS INSTITUTE (Cary, Estados Unidos). User's guide: estatistics (Cary, Estados Unidos). Raleigh, 1985. p.956.

TOTHILL, J.C.; HARGREAVES, J.N.; JONES, R.M. Botanal: a comprehensive sampling and computing procedure for estimating pasture yield and composition. I. Field sampling. Brisbane : CSIRODivision of Tropical Crops and Pastures, 1978. 20p. (Tropical Agronomy Technical Memorandum, 8).

TULLIO, R.R.; ALMEIDA, I.L.; BRUM, P.A.R. Influência da idade de desmama sobre o desempenho reprodutivo de vacas de cria, no Pantanal MatoGrossense. Corumbá : Embrapa-UEPAE de Corumbá, 1980. 3p. (Embrapa-UEPAE de Corumbá. Pesquisa em Andamento, 1).

TULLIO, R.R.; BRUM, P.A.R. Desenvolvimento de bezerros desmamados em diferentes idades, em pastagens cultivadas e em pastagem nativa, no Pantanal Mato-Grossense. Corumbá : EmbrapaUepae de Corumbá, 1980. 3p. (Embrapa-Uepae de Corumbá. Pesquisa em Andamento, 2). 